\section{El Fileteado Porteño: motivos decorativos en el margen de la comunicación publicitaria}

Mariana Bavoleo *

Resumen: En la década del '50, el Fileteado irrumpe en el arte popular porteño como una expresión netamente urbana unida a la decoración de vehículos. Desde una mirada sociosemiótica se reflexiona sobre su nacimiento, vida y transformación estilística sobre los márgenes de la comunicación publicitaria en la década del 2000.

A lo largo del recorrido se evidencia como la práctica atraviesa diferentes etapas: surge como motivo decorativo, se relaciona con los primeros vehículos de tracción a sangre, se solidifica como expresión sociocultural a nivel visual y discursivo, se estrecha con otros transportes como camiones y colectivos, es excluido por una prohibición normativa y finalmente se reinventa en el pasaje a nuevos soportes.

El proceso descubre un pasaje abierto desde los soportes vehiculares tradicionales, hacia los medios masivos publicitarios y hacia los objetos individuales cotidianos (instrumentos musicales, ropa, artículos de decoración, etc.). La transposición, el cambio de soporte o lenguaje de una obra o género, se hace recurrente y el Fileteado se soporta en medios gráficos, audiovisuales, murales, objetos de decoración e indumentaria.

¿Cómo lo que inicialmente se manifiesta con una expresión artística es recuperado por la comunicación publicitaria? Es uno de los cuestionamientos que guían la exploración de sus componentes visuales identitarios.

Palabras clave: arte popular - comunicación publicitaria - estilo - filetado porteño - género - motivos decorativos - sociosemiótica - transposición.

[Resúmenes en inglés y portugués en las páginas 134-135]

${ }^{(*)}$ Licenciada en Comunicación Social de la Universidad de Buenos Aires (UBA). Profesora en Enseñanza Media y Superior en Ciencias de la Comunicación (UBA). Diplomado Superior en Gestión Educativa (FLACSO). Profesora en la Universidad de Palermo, y en otras instituciones universitarias. Asesora y Capacitadora de cursos de Comunicación barrial y comunitaria. Se especializa en las áreas de Semiología, Arte y Estudios Comunicacionales; y Metodología e Investigación en Ciencias Sociales. También se desempeña como Analista de Comunicación y Admisión en la Maestría en Dirección de Empresas (MBAI EMBA) de la Universidad Torcuato Di Tella. 


\title{
Desarrollo
}

\author{
“¿Cómo le explicaría a un australiano lo del filete? \\ (...) Le diría que es un arte popular y \\ le filetearía un canguro". Martiniano Arce
}

\section{El momento fundacional}

El Fileteado se dará a conocer discursivamente como una forma singular de arte popular porteño, como una expresión netamente urbana y emergente de la ciudad de Buenos Aires, que estará estrechamente unida a la decoración de vehículos. Históricamente se situará su nacimiento en los inicios del siglo XX, pero su momento de auge se encontrará hacia mediados de la década del ' 60 .

Una carrocería, dos chicos y su picardía son las palabras recurrentes que se encuentran en las referencias metadiscursivas que hablan sobre el Fileteado Porteño. Al tratar de buscar su origen, casi como si fuera una casualidad, se narra un momento fundacional:

El filete nació por casualidad a fines del siglo XIX en una carrocería de Paseo Colón. Sus iniciadores fueron dos chicos, Vicente Brunetti y Cecilio Pascarella, que cumplían tareas subalternas como barrer, cebar mate, revolver pintura. En ausencia del pintor, el patrón les preguntó si se animaban a hacerlo: en esa época se usaba un gris deslucido. Los chicos hicieron bien el trabajo... Días después, el patrón les pidió que fueran a dar la última mano a otro carro. Si lo hacían el domingo, el lunes se cobraban. Los chicos aceptaron. $\mathrm{Al}$ ir encontraron un pote de pintura roja y tuvieron la idea de usarlo en los rebajos de la madera. El lunes, el patrón los levantó en peso: había que dar una nueva mano para poder cobrar el martes. En tanto, llegó el dueño y los chanfles rojos le gustaron. Y para sorpresa de todos, en los días siguientes, los dueños de carros del mercado cercano los llevaron para que les pinten los rebajes de color. A partir de ese momento, nació el fileteador (Barugel y Rubió, 2004).

En este sentido, se considera que no hay un primer artista, ni una fecha exacta, que permitan determinar con exactitud el inicio de esta práctica. Pero los testimonios y artículos periodísticos recopilados coinciden en que fueron tres inmigrantes italianos, dentro de las diferentes carrocerías existentes, los que desarrollaron casi contemporáneamente el Filetado: Cecilio Pascarella, Vicente Brunetti y Salvador Venturo, quienes posteriormente tuvieron como sus primeros continuadores a sus propios hijos.

A partir de la narración oral de aquel episodio, el Fileteado se dará a conocer discursivamente como una forma singular de arte popular porteño, emergente de la ciudad de 
Buenos Aires, que estará estrechamente unido a la decoración de vehículos. Muy paulatinamente sus motivos decorativos se esparcirán desde carros verduleros, lecheros y panaderos, hasta camiones y colectivos.

El origen etimológico de la palabra filete viene del latín filum (hilo) que significa línea fina que sirve de adorno; tiene su equivalencia en el inglés fillet, en el francés filet y en el italiano filetto. No obstante, Esther Barugel y Nicolás Rubió (2004) explican que en Buenos Aires se utilizan los términos filete y fileteado porteño indistintamente, para referirse al arte popular pictórico nacido en esta ciudad entre fines del siglo XIX y principios del XX; y se denomina fileteadores a los artistas que desarrollaron este particular estilo plástico. Emparentado en algún aspecto con el graffiti, por ser una técnica decorativa sobre superficies que transitaban en la vía pública, el Fileteado se hizo popular tanto por sus motivos característicos (líneas espiraladas, las hojas de acanto, las cintas celestes y blancas, bolitas, pájaros y dragones) como por sus frases risueñas a modo de refranes anónimos.

En la década del ‘40, con la aparición de los nuevos vehículos que lentamente irán sustituyendo al carro, el Fileteado adaptará sus formas y se establecerán claras diferencias:

(...) el fileteado en los colectivos tiene sus particularidades porque los dueños rechazaban las flores, principal marca de distinción de los carros y camiones verduleros. Entonces, hubo que incorporar distintas formas y colores de llaves y estrellados. También pasó a tener un protagonismo mucho mayor la gótica, ya que la carrocería del colectivo ofrecía paneles más grandes, donde escribíamos el nombre de la empresa (Pereira, 2004).

Justamente, Alberto Pereira (2004) sostiene que, con firuletes e iniciales muy adornadas, el gran desafío era trazar un filete continuo desde la puerta de un lado, hasta la del otro costado. También explica, que con el Fileteado, el transporte público absorbió las leyendas persistentes de la fraseología popular como por ejemplo: si quiere viajar mejor, córrase al interior", "no me gustan las mentiras, pero vivo del boleto" o "nena qué curvas y yo sin frenos".

Hacia las décadas del '50 y '60 era común ver carros, camiones y colectivos adornados con dichos que reflejaban juicios valorativos sobre la vida, el trabajo, la religión, el hombre, la mujer, los vicios y la familia. Entre los más conocidos se destacan: "EI sol sale para todos", "Muchos miran mi progreso pero pocos mi sacrificio", "Conduzco mi camión y... Dios me lo guía", "En la cama de los vivos, este gil duerme la siesta", "Charlemos... decime con que $1 / 2$... puedo llevarte al $1 / 4$ " "Tabaco, vino y mujer, echan al hombre a perder", "Cambio suegra por yarará, pago diferencia", "Si querés uno igualito laburá como Marcelito", "No te arrugues que la envidia te plancha", "Si tu estrella no alumbra... no apagues la mía", "El que envidiando vive, desesperado muere".

La particular combinación entre los elementos decorativos estéticos y el fuerte componente discusivo hacía del Fileteado una expresión particular porteña que, a través de variadas operaciones metafóricas tanto a nivel visual como discursivo, manifestaba los valores socioculturales del hombre de Buenos Aires [Ver Figuras 5, 6 y 7 en Catálogo de Figuras en la página 132]. 
El filete constituye una referencia cultural, en tanto expresión representativa de un sector cultural importante, pero también de un importante conjunto social que lo ha incorporado a sus vivencias. En este sentido, ha adquirido legitimidad social, especialmente en el contexto de la ciudad de Buenos Aires. Quienes han contribuido a dar forma al filete, han acumulado conocimientos y saberes en torno a prácticas específicas, que han sabido trasmitir a lo largo del siglo XX y que por tanto ya existen con independencia de los sujetos, para ser recuperados por otros sujetos y grupos sociales interesados. (...) (Maronese, 2007)

Para Cristian Sirouyan (2007), periodista especializado, durante más de medio siglo el filete contribuyó a definir la estética de Buenos aires, hasta que una reglamentación (un decreto ley dictado en 1975) lo eliminó de los vehículos de transporte público y lo prohibió, por considerarlo una ornamentación cargada y caótica, que dificultaba la lectura de recorridos y números de líneas.

En este sentido, para Carlos Achával, presidente de la Asociación Museo del Colectivo, la norma que prohíbe el fileteado es ridícula, sobre todo si se tiene en cuenta que ahora los enormes avisos publicitarios desplegados distraen mucho más a los automovilistas.

Sin embargo, a pesar de ser restringido de su lugar de origen, en el siguiente apartado se hará evidente como el Fileteado logra trascender y difundirse masivamente, durante más de seis décadas.

\section{La trascendencia de la imagen y los motivos decorativos}

Indudablemente, lo que moviliza a este trabajo es la persistencia de esta práctica que se vuelve aún más interesante al atravesar los comienzos del siglo XXI. Sin embargo, su importancia como referencia cultural no es la única razón que justifica su estudio; la tensión constituida entre su escasa documentación y reflexión teórica, y su revalorización y exposición a partir de la década del '90 es más que llamativa.

Claramente, una de las mayores dificultades es su distancia histórica, y resulta imposible estudiar el pasado sin una serie de intermediarios; es por esto que Peter Burke (2001) considera que las imágenes son un elemento tan legítimo como las fuentes bibliográficas y afirma que las pinturas, estatuas, murales y estampas pueden permite a la posteridad compartir las experiencias y conocimientos de las culturas del pasado. Esto implica revalorizar a la imagen como fuente o material de investigación para demostrar cómo diferentes motivos decorativos se consolidan como parte de la cultura porteña. ${ }^{1}$

Asimismo el nudo del conflicto pasaba inevitablemente por la delimitación del universo del artístico, razón por la cual se incluye/excluye del mismo a un fenómeno determinado por el valor estético que se le ha asignado, ya que históricamente los fileteadores reclamaban una revalorización de arte popular, mientras que los críticos negaban su existencia como fenómeno artístico. 
Se ha mencionado, que durante más de medio siglo, el Fileteado contribuyó a definir la estética popular de Buenos Aires; y a pesar de la prohibición municipal que restringió la práctica en las superficies de los colectivos porteños y debilitó su visibilidad pública, a mediados de la década del '90 se produce un nuevo despertar de los motivos decorativos bajo nuevos soportes y formas de comunicación incluidas la publicitaria.

Paralelamente, en el marco de este resurgimiento, este fenómeno popular es declarado como parte del Patrimonio Cultural de la Ciudad de Buenos Aires por la Legislatura Porteña en el año 2005, vinculando su valoración a la nueva proliferación de la práctica, que en esta última etapa se extenderá por los más diversos soportes: superficies murales, superficies publicitarias, objetos de consumo regional, indumentaria, volantes, afiches de propaganda política, pintura corporal y vidrieras comerciales.

En este punto, Alfredo Genovese (2004) quien se considera artista fileteador, sostiene que a partir de los años ' 90 , hay una revalorización de este fenómeno porque "el filete está más de moda que nunca, hay un resurgimiento de todo lo local, como también sucedió con el tango" y consecuentemente explica que muchas empresas utilizan sus motivos decorativos para hacer publicidad.

No obstante, en su evolución diacrónica, este resurgimiento generó por un lado la exageración (hiperbolización) y trascendencia de ciertos motivos decorativos como las hojas de acanto, las líneas espiraladas, las imágenes tangueras (fundamentalmente las de Carlos Gardel) y las cintas argentinas; y por el otro, la desaparición sistemática de las frases, dichos y refranes que vehiculizaban los saberes populares.

Si bien, esto será analizado en mayor profundidad en el próximo aparatado, cabe mencionar que dichos cambios parecen cuestionar la pertenencia del fenómeno a un único soporte (los transportes), legitiman su transposición y justifican su autonomía formal más allá de la configuración del género.

Puntualmente en el caso de la hoja de acanto, el principal motivo decorativo del Fileteado, Alois Riegl (1980) afirma que en la tradición de los antiguos ornamentos este elemento ha estado estrechamente unido al origen del capitel corintio, porque la figura del acanto no surge como una copia inmediata de un modelo natural, sino por el desarrollo de un proceso histórico-ornamental completamente artístico (Riegl, 1980). El autor sostiene que el arte está en indisoluble comunión con la naturaleza y las representaciones más antiguas de motivos vegetales que hoy conocemos, ya que incluso los mismos nos remiten hasta las obras de arte de la época del Antiguo Egipto.

Desde esta perspectiva, podría afirmarse que algunos de los elementos de configuración del Fileteado, como las hojas de acanto, las flores y las líneas espiraladas, hacen referencia a los estilos clásicos de motivos vegetales helenos y antiguo-orientales de la arquitectura de principio de siglo, que actualmente se resignifican en sus transposiciones estilísticas. 


\section{Los motivos decorativos, un análisis comparativo}

Focalizando en la temática propuesta, se toma como objeto de estudio específico la construcción de los motivos decorativos populares que se articulan en la práctica del Fileteado y llegan a transformarse en íconos de lo porteño, a través de las décadas del '60 y 2000.

La elección de las mismas se corresponde con el grado de alta visibilidad y revalorización de la práctica, aunque cabe aclarar que las condiciones de producción de dichos discursos se encontrarán no sólo en los motivos decorativos de los inicios de la década del '40, sino también en la arquitectura de principio de siglo, y en los estilos clásicos de motivos vegetales helenos y antiguo-orientales, entre otras.

En otras palabras, existen ciertas propiedades significativas previas, que al relacionarlas con las condiciones productivas (otros discursos que restringirán al discurso de análisis), se transformarán en huellas que nos permitirán reconstruir el proceso de producción. (Verón, 1987).

Con respecto a los motivos decorativos del Fileteado, pueden rastrearse propiedades significativas como las hojas de acanto, las flores y las líneas espiraladas en los orígenes de los estilos clásicos egipcios y griegos. En la Figura 1 [Ver Catálogo de Figuras en la página 132] se observa un capitel corintio formado por hojas de acanto y en la Figura 2 [Ver Catálogo de Figuras en la página 132] se observa en detalle la representación de la misma hoja. Lo interesante, es que la representación de este motivo vegetal se relaciona con discursos que versan sobre la resistencia y la superación de la adversidad.

Este elemento vegetal, junto con las flores y líneas espiraladas [Ver Figura 3 en el Catálogo de Figuras en la página 132], parecen ser algunos de los elementos significativos que se relacionan con las condiciones de producción.

Quizás sean las hojas de acanto el elemento más común de todo filete, y sobre las cuales el pintor suele innovar más. De hecho, hoy en día es posible en muchos casos reconocer al autor de un filete por el estilo de sus hojas de acanto. Según declaró alguna vez el maestro León Untroib, estos motivos han sido copiados de las columnas corintias, muy populares en las grandes construcciones de la Grecia antigua, sobre todo en el período Helenístico (Brabuco, 2008)

Puntualmente, la ornamentación de vehículos en la ciudad de Buenos Aires hacia comienzos de la década de '40, se encontrará restringida por estos elementos decorativos. Así el Fileteado tendrá condiciones de producción discusivas no sólo relacionadas con estos motivos, sino también relacionadas con esa temprana decoración de carros de tracción a sangre. Si bien las imágenes documentadas no permiten la diferenciación de colores en esta etapa, se observan fundamentalmente motivos decorativos conformados por líneas onduladas, espiraladas, flores y en algunos casos pequeñas hojas de acanto.

Focalizando en estas primeras composiciones decorativas, se puede afirmar que las mismas son simples y que algunas se encuentran organizadas simétricamente. Sus figuras son planas, sin marcación de volumen (ausencia de luces y sombras) ni contrastes llamativos. 
Hay que advertir que a mediados de la década, esta decoración se extiende a otros vehículos como carros verduleros, lecheros y panaderos; y luego, con la aparición de nuevos vehículos, que irán sustituyendo paulatinamente al carro, el Fileteado adaptará sus formas para pasar a camiones y colectivos en la década siguiente.

Asimismo entre otras de las condiciones, también se encuentran las referencias a la sabiduría popular y a las leyendas de la una cultura oral que se transmitía en frases o en canciones. En relación a los motivos decorativos, se podría decir que en las etapas previas a la década del '60, se observará la consolidación de algunos rasgos estilísticos como la incorporación de hojas de acanto, las líneas onduladas, los espirales, las flores y la aparición de algunas frases, resaltadas con luces y sombras, dispuestas simétricamente, que gradualmente irán constituyendo algunas condiciones de previsibilidad.

\section{La década del '60: Consolidación y auge}

A mediados de la década del '50 parecen confluir una serie de factores, que podrían indicar el pasaje del estilo al género constituyendo gradualmente algunas condiciones de previsibilidad.

En la dimensión retórica y en los mecanismos de configuración del Fileteado, hay que tener en cuenta no sólo el tipo de soporte sino fundamentalmente la composición y estructuración de los diseños, sus características estéticas, sus elementos y la incorporación de figuras.

Con respecto a los primeros diseños fileteados, los mismos se remontan a ornamentos pintados con esmalte sintético en los paneles laterales y frontales, en las ruedas, en las varas y en las barandas de los carros, camiones y colectivos.

En las imágenes documentadas se observa que los colores utilizados eran puros y vivos, prácticamente saturados [Ver Figuras 4, 5, 6 y 7 en Catálogo de Figuras en la página 132]. Si focalizamos en la organización de los mismos, se observa que los primeros dibujos tenían una composición simple, sin aplicación de luces y sombras. Sin embargo, hacia el final de la década del '50 se distingue la adopción de una técnica específica: la marcación de sombras y luces; el llamado 'yapan' (barniz con un mínimo toque de pintura).

Consolidada en la década del '60, se observa (en casi todas las composiciones) como las figuras y frases están marcadas con luces y sombras. Esto genera la acentuación del volumen y la profundidad de las formas, resaltadas por un marcado contraste de color de figura-fondo.

Además, hay que señalar que en las imágenes obtenidas el equilibrio de la composición usualmente se mantiene por la simetría de los diseños, con composiciones recargadas.

Todos estos elementos, se articulan y combinan no sólo con particulares características de composición simétrica, con una estructuración recargada de los diseños, con gamas saturadas y con colores vivos y brillantes, sino también con figuras específicas. Es decir, que estos rasgos retóricos enumerados y descriptos a su vez se relacionan con dos figuras predominantes: la iteración y la metáfora. 
Por un lado, con respecto a la iteración, la misma puede definirse como una operación ${ }^{2}$ de adjunción que se caracteriza por la repetición. Mientras que, con respecto a la metáfora, la misma puede definirse como una operación combinada de supresión-adjunción, en la cual se sustituye un término por otro en base a la comparabilidad por similaridad. En esta operación los términos sustituidos y términos los sustituyentes pertenecen a universos separados.

Cuanto mayor es la separación de estos universos más "eficaz" y contundente es la metáfora, y es mayor la evidencia de un trabajo sobre el lenguaje (lenguaje figurado, función poética). (...) Una de las particularidades de la metáfora es que en la operación de unir a través de la similaridad dos universos distantes entre sí, fija y cierra el sentido (Soto, 2001).

Asimismo, vinculado con este concepto de figura retórica, es necesario especificar que la metáfora va más allá de esta función poética. Retomando los aportes de Lakoff y Johnson, se puede sostener que la metáfora no se restringe solamente al lenguaje, sino que impregna la vida cotidiana, el pensamiento y la acción.

La esencia de la metáfora es entender y experimentar un tipo de cosas en términos de otra (...) Esa misma sistematicidad que nos permite comprender un aspecto de un concepto en términos de otro, necesariamente ha de ocultar otros aspectos del concepto en cuestión (Lakoff y Johnson, 1995).

De esta manera, cuando los autores explican cómo los conceptos pueden estar estructurados metafóricamente, se refieren a que los mismos están parcialmente estructurados, pueden ser entendidos de ciertas maneras pero no de otras. Consecuentemente, con esta argumentación sostienen que incluso los procesos de pensamiento humano son en gran medida metafóricos.

En relación con el Fileteado, Albero Pereira (2004) sostiene que el mismo "no se realiza solamente con fines estéticos, sino también como manifestación de los valores socioculturales del hombre de Buenos Aires."

Esto se percibe en las variadas operaciones metafóricas que se expresan en esta etapa, que vehiculizan juicios valorativos sobre la vida ("EI sol sale para todos"), el trabajo ("Muchos miran mi progreso pero pocos mi sacrificio"), la religión ("Conduzco mi camión y... Dios me lo guía"), el hombre ("En la cama de los vivos, este gil duerme la siesta"), la mujer ("Charlemos... decime con que $1 / 2 \ldots$ puedo llevarte al $1 / 4$ "), los vicios ("Tabaco, vino y mujer, echan al hombre a perder”) y la familia ("Cambio suegra por yarará, pago diferencia”). En este sentido, siguiendo el desarrollo de Lakoff y Johnson (1995), puede afirmarse que si las metáforas impregnan la vida cotidiana y los valores, las creencias de la sociedad no pueden ser independientes porque forman parte de un sistema de conceptos metafóricos. Las creencias, de la cultura porteña en este caso, serán entonces coherentes con la estructura metafórica de los conceptos fundamentales de la misma.

Finalmente, en lo que refiere al análisis temático de esta década, se puede concluir que los temas son diversos e heterogéneos y están constituidos tanto desde lo textual y como 
desde lo visual. Los mismos aparecen fuertemente relacionados con los temas de la vida cotidiana porteña y los saberes propios de la época. La cotidianidad se percibe por un lado en carácter coloquial, afirmativo y certero de las frases (estructuradas metafóricamente), y por el otro en la recurrencia e insistencia visual de las formas estéticas (reforzadas por la iteración) a lo largo de toda la década.

\section{La década del 2000: Revalorización y ¿transformación?}

De la misma manera que para la década anterior, puntualizando en la dimensión retórica y en los mecanismos de configuración del Fileteado, puede afirmarse que con respecto a la composición, en la década del 2000 se mantienen los parámetros tradicionales de simetría y equilibrio. También se presentan diseños asimétricos, y en esos casos se continúa respetando la utilización de la diagonal para organizar el diseño.

Aunque, a diferencia de la década '60, se observan algunas aplicaciones que no respetan estos principios, rompiendo no sólo con el equilibrio compositivo sino también con la presencia del marco interno y externo predominante en los años anteriores.

Si bien, en las mayoría de las composiciones se incorpora un marco, es característica la presencia de los marcos internos (con ausencia del externo) conformados por hojas de acanto, cintas celestes y blancas (bandera Argentina), y líneas onduladas.

En consecuencia, a partir de lo observado, se podría sostener que los dos niveles de ornamentos y marcos, muy diferenciados en la década del '60, no se presentan en las composiciones de la década del 2000 como una invariante fundamental. No obstante, los diferentes niveles se presentan alternadamente en diversas composiciones, $\mathrm{y}$ tanto los marcos internos como los diseños en general parecen ser mucho más complejos y recargados, no por repetición sino por el gran tamaño de sus formas y por la combinación de elementos, diferenciándose claramente de las décadas anteriores.

Con respecto a la técnica de marcación de sombras y luces, la misma se observa en todos los casos y en heterogéneos grados, como una herramienta recurrente para dar profundidad y volumen.

Asimismo, las gamas de colores predominantes oscilan entre los azules, los rojos y los amarillos, pero se añaden también los verdes, los violetas y magentas. A pesar de que se mantiene la incorporación de tonalidades puras y saturadas, en la mayoría de los casos, las mismas se presentan combinadas con tonalidades terrosas o apasteladas.

Estas nuevas combinaciones y gamas de colores, están relacionadas estrechamente con los cambios en los soportes (objetos, cuerpo, medios gráficos y audiovisuales, vehículos), superficies (vidrios, láminas vinílicas, papel, plásticos, metales, etc.) y materiales (óleos, acrílicos, tintas de impresión, combinadas con esmalte sintético).

Frente a esta caracterización puede sostenerse que, en comparación con la década del '60, en la del 2000 los elementos continúan organizados en base a características de composición simétrica pero incorporando su ruptura en algunos casos; persisten articulados con una estructuración recargada de los diseños pero no por repetición sino por el aumento 
de la dimensión de sus formas; y subsisten en gamas saturadas y en colores vivos pero en combinación con tonalidades terrosas y apasteladas.

Asimismo, estas nuevas adaptaciones y cambios se relacionan con dos figuras predominantes: la hipérbole y la metonimia.

Por un lado, con respecto a la hipérbole, la misma puede definirse como una operación de adjunción al igual que la iteración, sin embargo en este caso se caracteriza por el agrandamiento y la exageración. Esta se distingue exclusivamente en el nivel de lo visual y predomina en los fileteados a lo largo de toda la década.

La Figura 8 es representativa de la utilización de esta figura. Allí, se puede observar un corazón de fibra de vidrio (de 1.20 x 1.40 metros) decorado para una muestra artística en la vía pública promocionada por la Fundación Favaloro y el Gobierno de la Ciudad de Buenos Aires. La ornamentación del objeto está realizada con esmalte sintético y se presenta con una composición asimétrica, no enmarcada, con grandes hojas de acanto y líneas espiraladas, que se entrelazan con una cinta ondulada celeste y blanca muy gruesa (bandera Argentina). También se puede percibir un efecto de volumen y profundidad acentuado, resaltado por un marcado contraste de figura-fondo. No obstante, en esta composición el elemento predominante es la cinta celeste y blanca, que impregna el espacio disponible por su exagerado tamaño.

Podría decirse, que la figura de la hipérbole se articula en referencia al tamaño de las formas de la década del '60. Porque si en dicha época el espacio parecía saturado por la repetición de diseños y pequeñas formas, en la del 2000 el espacio parece saturarse por el agrandamiento de los elementos.

Por otro lado, con respecto a la metonimia, esta figura puede especificarse como una operación de supresión- adjunción en la cual se sustituye un término por otro en base a la contigüidad.

Los términos sustituidos y sustituyentes pertenecen al mismo universo, se trata pues de una sustitución que opera como desplazamiento dentro del mismo (...) Así como decíamos con respecto a la metáfora que esta cierra el sentido, la metonimia lo abre en este desplazamiento en el mismo universo (Soto, 2001)

Es decir mientras que metáfora opera por condensación, la metonimia opera por desplazamiento. En este punto, Christian Metz $(1979)^{3}$ sostiene que estas dos figuras constituyen las grandes figuraciones propias del orden simbólico, y aunque no sean las únicas se bosquejan como clases de súper- figuras, como categorías de reunión por un lado de las figuras de similaridad y por el otro de las figuras de contigüidad.

No obstante, sin lugar a dudas, la transformación más fuerte se ocasiona con la desaparición de las frases populares. La imagen cobra protagonismo absoluto, y las figuras retóricas predominantes parecen ser consecuentes con este cambio; incluso desde lo temático, en la década del 2000, los motivos que conformarán los temas se esbozarán fundamentalmente a partir de formas estéticas.

Asimismo en este proceso se marcarán diferencias con respecto a los temas de la década del 60': desaparecerán algunos, persistirán otros y se incorporarán nuevos. Específicamente desaparecen los temas de "la familia como desgracia", "las mujeres como objeto 
de deseo", "el trabajo como esfuerzo y sacrificio", "el hombre pícaro y compadrito", "Dios como guía del destino y la vida"; persisten "la argentinidad" no sólo vinculada al orgullo del patriotismo sino también a lo propio, a lo local y a lo simbólico, y "el tango" sin estar asociado exclusivamente a Gardel sino además a lo porteño; y se incorporan "los ídolos argentinos", "el fútbol como pasión deportiva" y "la política como causa popular".

La desaparición de ciertos temas estará estrechamente relacionada con la pérdida de las frases, el predominio de la imagen y con la incorporación de marcas y slogans; estos pasaran a sustituir (en muchos de los casos) el lugar central que ocupaban las frases risueñas [Ver Figuras 12, 13, 15 y 16 en Catálogo de Figuras en la página 133].

De forma gradual, los temas se irán relacionando con la representación de lo porteño pero desde otro ángulo: el de la revalorización y el fortalecimiento de los íconos identitarios, distanciándose de la transmisión de los valores de la vida cotidiana y los saberes compartidos). Mientras que en el caso de los motivos este viraje se percibe, por un lado en el nuevo protagonismo que adquieren las banderas argentinas y los rostros de los ídolos que se envuelven en ellas (asociados metonímicamente, ver Figura 10 en Catálogo de Figuras en la página 133), y por el otro en la reiterada insistencia visual de las formas estéticas (reforzadas por la hipérbole, ver Figura 11 y 16 en Catálogo de Figuras en la página 133) a lo largo de toda la década.

\section{Una mirada desde la matriz del género y estilo}

A lo largo de su desarrollo la semiótica se ha relacionado con diferentes corrientes y perspectivas. Según Oscar Steimberg, es previsible que las mismas se superpongan en su estudio, ya que la misma existe en un estado impuro:

Si se dice que la semiótica debe leerse a partir de los conceptos de signo y de código y de las críticas que han sucedido de estos conceptos (...) se está postulando que debe ser leída desde proposiciones y desarrollos de la lingüística y otras disciplinas internas y externas al campo de las ciencias sociales. Si en cambio se propone la consideración de sus textos desde una perspectiva filológica, se está privilegiando su relación con aspectos de la historia de la cultura que han conformado una contextualización posible (Steimberg, 1998).

En este marco, el autor hará énfasis en el estudio del género para dar cuenta de las relaciones entre los dispositivos discursivos potenciados por la expansión de los medios masivos. Así dará cuenta de que los géneros existen e insisten en los medios y que cuando se focaliza en los nuevos dispositivos mediáticos el fenómeno de la transposición ${ }^{4}$ cobra una importancia muy relevante.

El concepto de género puede definirse como "clases de textos u objetos culturales, discriminables en todo lenguaje o soporte mediático, que presentan diferencias sistemáticas entre sí y que en su recurrencia histórica instituyen condiciones de previsibilidad en distintas áreas de desempeño semiótico." (Steimberg, 1998). Esta definición permite evidenciar que 
si el género está presente en diversos soportes y lenguajes, instituyendo previsiblilidades, una de sus funciones es la de facilitar el contacto y la comunicación.

Sin embargo, Steimberg sostendrá que si el género es la institución que permite encuadrar los discursos de determinadas formas, el estilo serán las maneras de hacer que le dan unidad a las diversas formas. Para el autor, el estilo se define como "la descripción de los diversos rasgos que por su recepción y su remisión a modalidades de producción características permiten asociar entre sí objetos culturales diversos, pertenecientes o no al mismo medio lenguaje o género" (Steimberg, 1998).

Ahora, si se piensa en este fenómeno artístico desde las categorías del género y el estilo, pueden puntualizarse sus características y su relevancia comunicativa.

Su desarrollo permite argumentar que, en las etapas previas a la década del ' 50 , se distingue la organización de ciertos motivos decorativos porteños como rasgos estilísticos que gradualmente constituirán condiciones de previsibilidad, auspiciando en la década del ' 60 la constitución del género artístico. En esta década se produce simultáneamente la consolidación metadiscursiva y la restricción del área de desempeño semiótico: los rasgos estilísticos se convierten en un género pictórico con denominaciones que remiten a espacios relacionados con el arte popular, vinculándose con algunos subgéneros como el retrato, el paisaje y el dicho popular.

Entonces como género artistico, el Fileteado, acota temas relacionados con la vida popular porteña, se representa retóricamente por elementos decorativos y por operaciones metafóricas, y establece enunciativamente un contrato de lectura complementario que excluye a todo aquel que no comparta el saber popular que se enuncia como una verdad preestablecida.

Sin embargo, en la década del 2000, por efecto de las transformaciones y desapariciones, el Filete Porteño se aleja de la utilización metafórica discursiva y se focaliza en la hiperbolización de los motivos decorativos, la imagen se sobredimensiona y se hace plena.

Al mismo tiempo se aplica con funciones diversas, en heterogéneos soportes, y en espacios no solamente circunscriptos a la decoración y a lo artístico, sino también, estrechamente relacionados con una función comercial y publicitaria. Los motivos decorativos pueden visualizarse tanto en campañas publicitarias de Much Music, Pepsi, Coca-Cola, Aiwa y Galerías Pácifico; hasta en las vidrieras, fachadas y artículos regionales de los negocios de La Boca, San Telmo y Almagro.

Otras de las marcas, que también incorporan motivos fileteados relacionados con el fútbol, es Rexona. En la Figura 14 [Ver Catálogo de Figuras en la página 133], se observa una de las publicidades en vía pública de la marca (Gigantografía en vinilo sobre panel metálico, ubicada frente a la cancha del Club Boca Juniors en el barrio de La Boca). En la misma se distingue una composición digitalizada, simétrica y enmarcada con líneas onduladas, en la cual se añaden ornamentos como las hojas de acanto, las bolitas, las estrellas y las cintas celestes y blancas. A su vez, está dividida en tres partes, la parte superior en la que se utiliza un óvalo para reproducir una caricatura de un jugador de fútbol (transpirando) y un hincha (festejando); la central donde se lee: "El jugador tiene que transpirar la camiseta, el hincha sólo quererla" rodeado de hojas de acanto, bolitas y líneas onduladas; y la inferior que se lee en continuidad el slogan "Rexona no te abandona" junto al logotipo de la marca reproducido con una cinta celeste y blanca. 
Por supuesto, que en confrontación, los temas pueden ser similares en algún aspecto y estar provistos de significados completamente diferentes. Ya que al igual que los signos, afirma Cesare Segre (1988), los temas son polisémicos e identificarlos es un acto eminentemente histórico. Los discursos de querer la camiseta, los colores, la bandera, de revalorizar la identidad nacional a través de lo icónico y de crear nuevos ídolos populares, son particularmente porteños y atraviesan transversalmente todos los temas de la época.

Es importante destacar, a modo de síntesis, que la práctica atraviesa diferentes etapas: surge como motivo decorativo, se relaciona con los primeros vehículos de tracción a sangre, se solidifica como expresión sociocultural a nivel visual y discursivo, determina su condición genérica, se estrecha con otros transportes como camiones y colectivos, es excluido por una prohibición normativa, y finalmente se reinventa transgenéticamente en el pasaje a nuevos soportes, sin poder evitar que la publicidad haga propia sus formas identitarias. Por efecto de las transformaciones y desapariciones el Filete comienza a utilizarse con funciones diversas, en diversos soportes, y en espacios no solamente circunscriptos a la decoración y a lo artístico, sino también estrechamente relacionados con una función comercial. El caso de Rexona es claro: ¿cómo lo que inicialmente se manifiesta con una expresión artística es recuperado por la comunicación publicitaria? El tipo de construcción que se había transformado de elemento decorativo en género, deviene como producto estilístico transgenérico. La transposición, el cambio de soporte o lenguaje de una obra o género, se hace recurrente y el Fileteado se soporta en medios gráficos, audiovisuales, murales, objetos de decoración e indumentaria. Podría decirse, que lo que en un inicio, se manifiesta con una expresión artística es recuperado por la comunicación publicitaria al explotar sus componentes visuales identitarios.

En relación con este tipo de transformaciones, Mario Carlón afirma que en cada pasaje el género cumple una función distinta. Esto se debe no sólo a los cambios del lenguaje y soporte, sino también a la sobredeterminación de los diferentes juegos de lenguaje que le son propios (Carlón, 1997).

En este punto, habría que preguntarse porque en esta última etapa fundada por la transposición, se produce un pasaje tan abierto desde los soportes vehiculares tradicionales, hacia los medios masivos publicitarios y hacia los objetos individuales cotidianos (instrumentos musicales, ropa, artículos de decoración, etc.).

Sin intentar enunciar reflexiones cerradas, podría decirse que uno de los factores fundamentales, en la incorporación del Fileteado en soportes tan disímiles, es la resignificación de los estereotipos relacionados con las formas decorativas identitarias porteñas, que resquebrajan la fijeza de los motivos y significados de las décadas anteriores.

Estilización y resignificación, en el sentido de que los motivos decorativos y temáticos asociados a lo porteño y a lo argentino, se retoman para ponerse a disposición de funciones, formas y soportes no tradicionales, completamente variados, desde objetos artísticos y de consumo (bastidores, botellas, mates, instrumentos musicales, ropa, carteras, etc.), transportes (colectivos, micros escolares y camiones en menor medida), fachadas (restaurantes, tanguerías, casas de artículos regionales y puestos de diarios), hasta publicidades (de desodorantes, de supermercados, de cigarrillos, de programas de televisión, de diarios, etc.). No obstante, tampoco puede ignorarse, que dichos cambios también se ven potencializados por el proceso de digitalización y serialización de motivos decorativos. Es la po- 
sibilidad de reproductibilidad, la que en cierta medida impulsa la creación del nosotros publicitario desde los iconos que articulan la identidad porteña. Un proceso que apela desde la imagen, desde lo pasional y lo sentimental, desde las marcas y slogans, a reforzar una identidad colectiva.

La idea de repetición resulta de enorme importancia para entender la peculiaridad de la cultura visual del siglo xx. Unida a la consolidación y al extraordinario desarrollo de la reproductibilidad tecnológica dentro de la producción cultural visual, la repetición, junto con la serie de conceptos interrelacionados que contribuye a generar y mantener, resulta un rasgo ineludible de la práctica cultural de masas (Darley, 2002).

La proliferación de imágenes a las que rápidamente dio lugar el proceso de digitalización, resulta fundamental para entender el predominio que han adquirido la forma y los motivos decorativos en la multitud de prácticas estéticas de la cultura de masas.

Entonces, cabría preguntarse... ¿Qué persiste del fenómeno artístico en las resignificaciones publicitarias?

\section{Notas}

1. Cabe destacar que el presente artículo reúne algunas reflexiones, interrogantes y conclusiones, que surgen de un proceso de investigación personal llevado a cabo en el transcurso de los dos últimos años. El mismo tuvo como partida una base documental conformada por la recopilación de 250 imágenes y 50 artículos periodísticos.

El corpus de imágenes se restringió: Para la década del '60, imágenes fotográficas de vehículos de transporte, en los que se observan elementos y motivos decorativos que esbozan al Fileteado Porteño; y para la década del 2000, imágenes fotográficas de diferentes soportes donde se vehiculizan elementos y motivos decorativos característicos del Fileteado. Entre ellas imágenes de murales, publicidades, objetos, indumentaria y vía pública.

2. El concepto de operación es retomado del desarrollo teórico del Grupo u, el mismo entiende que la figura es el resultado del cruce entre un tipo de operación y una unidad sobre la cual opera. De esta manera, se distinguen dos tipos de operaciones: las sustanciales que pueden ser de adjunción (añaden unidades) y/o de supresión (suprimen unidades), o las relacionales que alteran el orden de las unidades sin modificar su naturaleza.

3. En primer lugar, hay que aclarar que Metz tiene como objeto de análisis al discurso cinematográfico, pero sus afirmaciones son pertinentes para este desarrollo. En segundo lugar, cabe destacar que el mismo retoma para su análisis a Jacques Lacan, y para este último la metáfora será equivalente al mecanismo de condensación: la sustitución del significante por el significante. Mientras la metonimia será equivalente a mecanismos del desplazamiento: la conexión del significante con el significante.

4. El autor habla de transposición cuando un género o producto textual particular cambia de soporte o de lenguaje. 


\section{Referencias Bibliográficas}

Barugel, E., y Rubió, N. (2004). El filete porteño. Bs. As: Maizal Ediciones.

Brabuco, C. (2006). La(s) Entrevista(s) del Mes [en línea] El Suplemento, martes, 28 de febrero de 2006, recuperado en: http://www.elsuplemento.com.ar.

Burke, P. (2001). Visto y no visto: El uso de la imagen como documento histórico. Barcelona: Ed. Crítica SL.

Carlón, M. (1997). "Vida y sobrevida de un transgénero alto: el retrato en la cultura y en los medios”. Material de la cátedra Semiótica de los medios y géneros contemporáneos, UBA, Fac. de Cs. Sociales.

Cirio, N. (1996). El filete porteño, biografía crítica y definición conceptual, en Actas de Segundas Jornadas de Estudios e Investigaciones en Artes Visuales y Música. Universidad de Buenos Aires: Facultad de Filosofía y Letras.

Darley, A. (2002). Cultura visual digital. Barcelona: Paidós.

Genovese, A. (2005). Fileteado Porteño. Bs. As.: Ed. Grupo Ediciones Porteñas. (2004). Tratado del Fileteado Porteño. Bs. As.: Ed. Grupo Ediciones Porteñas.

Giudici, A. (2004). "El filete porteño - Entre el pop art y el realismo mágico", texto del curador de la muestra de Alberto Pereira en el Centro Cultural de la Cooperación. Buenos Aires: Departamento de Ideas Visuales CCC, año 2 número 2.

Grupo U. (1897). Retórica general. Buenos Aires: Paidós.

Lakoff, G., y johnson, M. (1995). Metáforas de la vida cotidiana. Madrid: Cátedra.

Madrazo, C. (2001). "Martiniano Arce" [en línea]. La Nación.com, domingo 21 de enero de 2001, recuperado en: http://www.lanacion.com.ar.

Metz, C. (1979): "Retórica y lingüística: El gesto jakobsoniano" de Psicoanálisis y cine: El significante imaginario. Barcelona: Gustavo Gilli.

Panofsky, E. (1979). El significado en las artes visuales. Alianza: Madrid.

Perinola, M. (1997). La estética del siglo veinte. Madrid: Machado Libros, Colección Léxico de Estética.

Petersen, E. (2005). "El graffiti en Buenos Aires", [en línea], El portal de México, recuperado en: http://elportaldemexico.com/artesplasticas/artesplasticas.htm [Consultado sept 2005] Rubió, N. (2004). "Notas breves sobre la historia del filete", texto escrito para la muestra de Alberto Pereira en el Centro Cultural de la Cooperación de Buenos Aires.

Riegl, A. (1980). Problemas de Estilo. Fundamentos para una historia de la ornamentación. Barcelona: Ed. Gustavo Gili S.A.

Segre, C. (1988). Principios de análisis del texto literario. Cap “Tema/motivo”. Barcelona: Ed. Crítica.

Sirouyan, C. (2005). “Cultura: una norma que lleva treinta años de vigencia” [en línea]. Clarín.com, viernes 17 de junio de 2005, recuperado en http://www.clarín.com.

Soto, M. (2004). Operaciones retóricas. Documento de cátedra: Semiótica de los Géneros Contemporáneos, UBA. 2001. Versión revisada 2004. Buenos Aires.

Steimberg, O. (1998). Semiótica de los medios masivos. El pasaje a los medios de los géneros populares. Buenos Aires: Atuel Colección del Círculo.

Verón, E. (1987). La semiosis social. Buenos Aires: Ed. Gedisa.

Traversa, O. (1997). Cuerpos de papel. Barcelona: Gedisa, Colección El mamífero parlante. 


\section{Catálogo de Figuras}

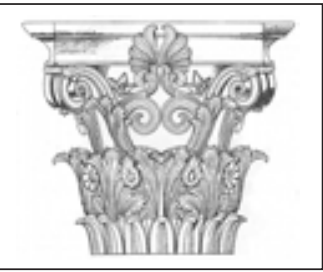

F1.

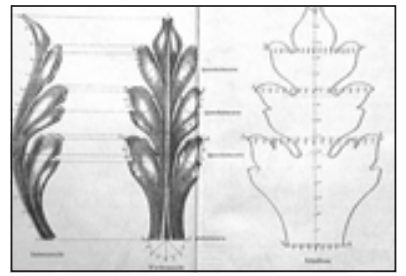

F2.

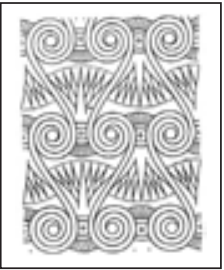

F3.

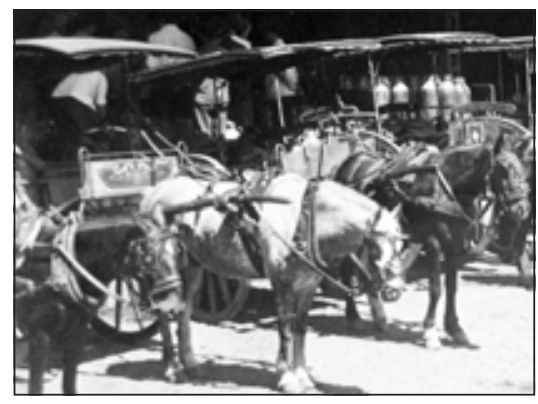

F4.

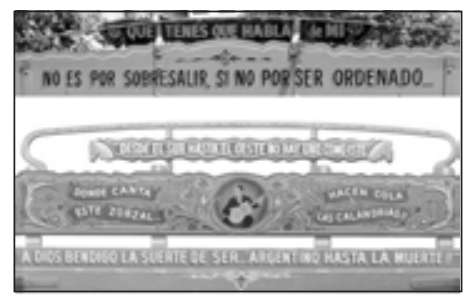

F6.

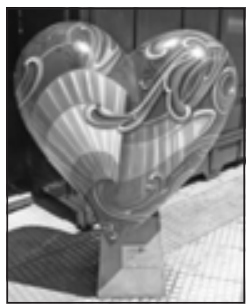

F8.

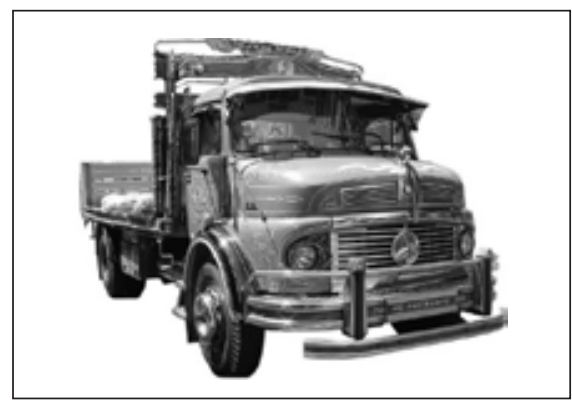

F5.

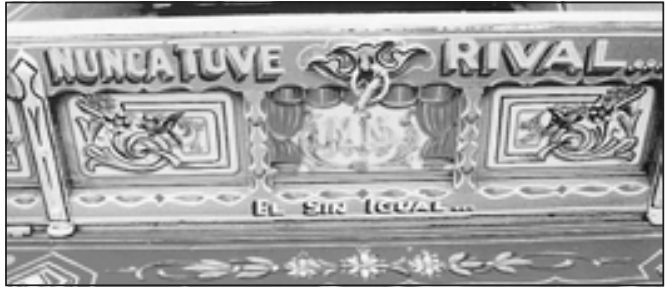

F7.

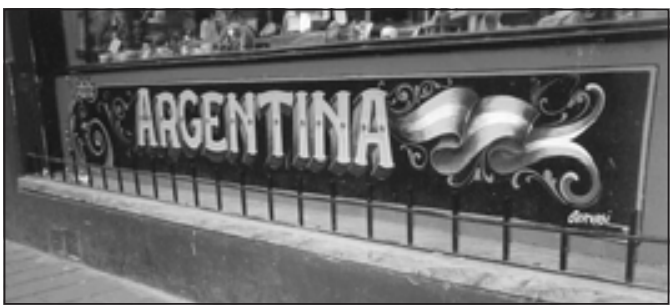

F9. 


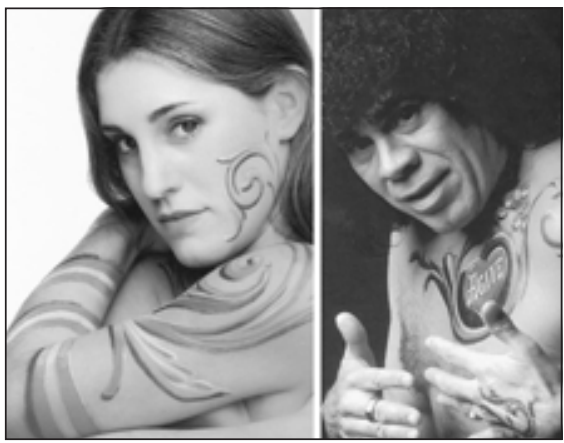

F10.
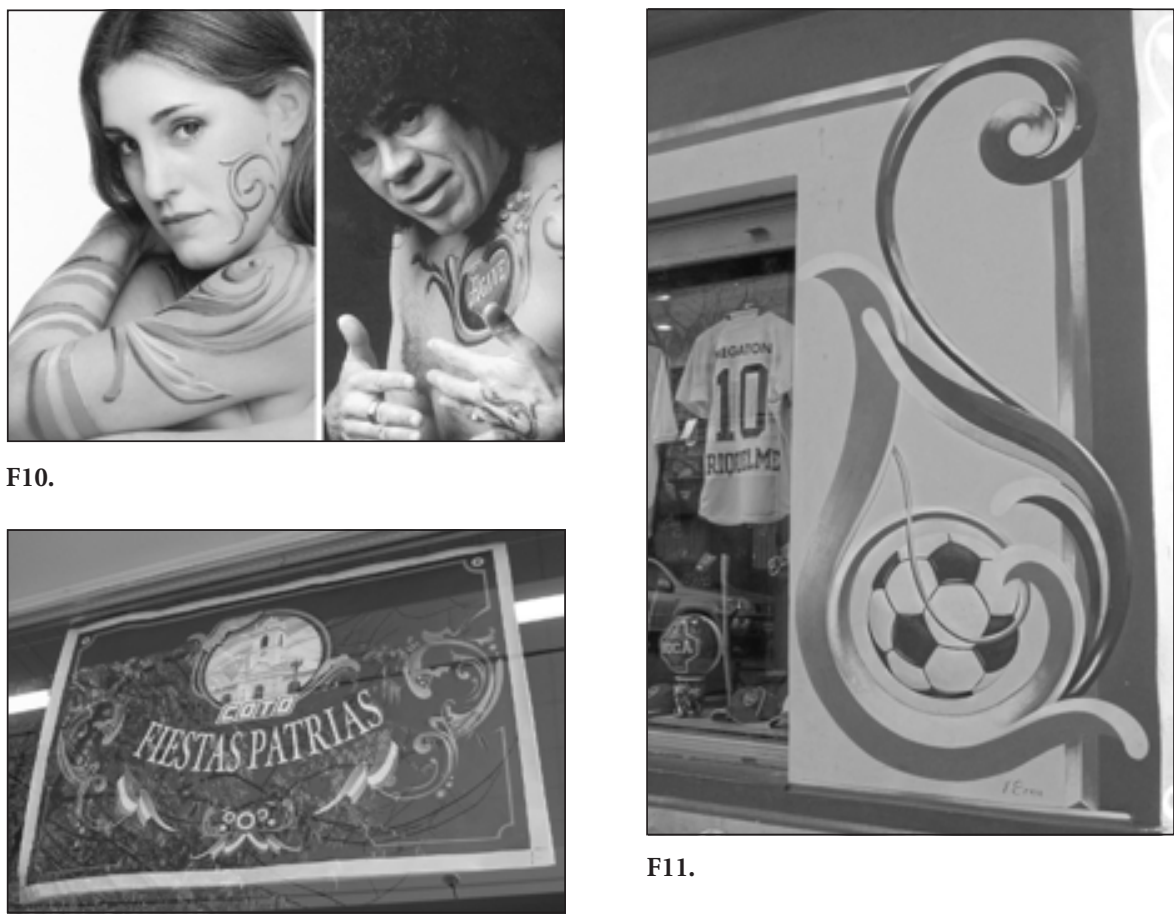

F11.

F12.

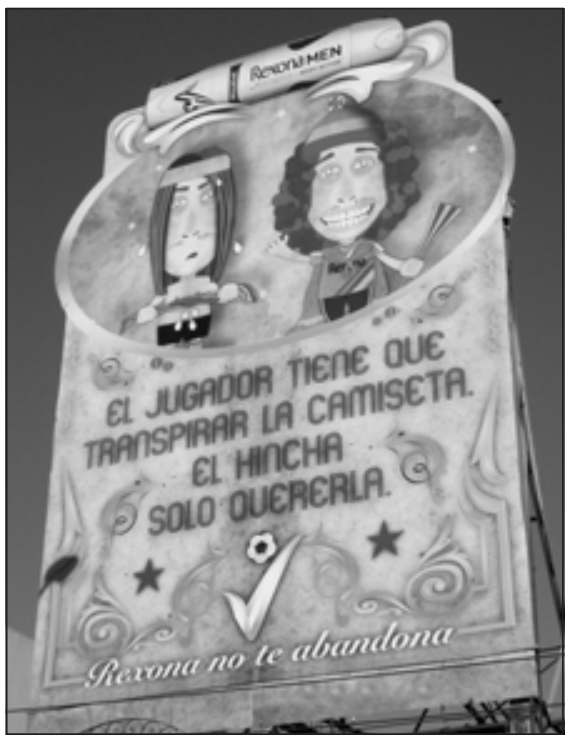

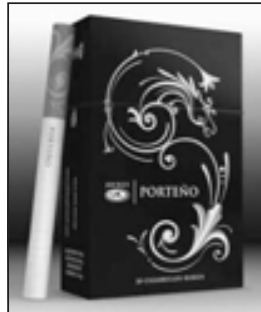

F13.

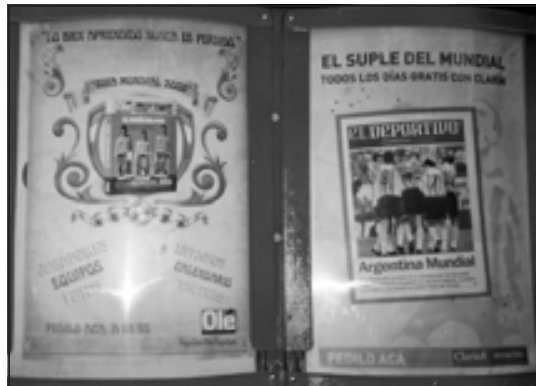

F15.

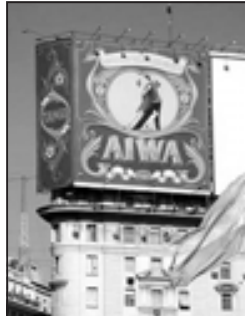

F16.
F14. 
Figura 1. Detalle de capitel corintio. Fuente. Riegl A. (1980). Figura 2. Detalle de hoja de acanto. Fuente. Riegl, A. (1980).

Figura 3. Arte del antiguo oriente. Detalle de líneas espiraladas. Fuente. Riegl, A. (1980).

Figura 4. Playa de carga de carros lecheros. Década del '40. Fuente. Archivo General de la Nación Argentina.

Figura 5. Camión fileteado. Década del '60. Fuente. Genovese, A. (2007).

Figura 6. Partes traseras de camiones fileteados. Década del '60. Fuente. Genovese, A. (2007).

Figura 7. Parte trasera de camión fileteado. Década del '60. Fuente. Genovese, A. (2007).

Figura 8. Corazones Vivos, Muestra de Arte Urbano a Cielo Abierto. Fuente. Fundación Favaloro y Gob. de la Ciudad de Bs.As (2006).

Figura 9. Marquesina de casa de artículos regionales, Barrio de Once (Abasto). Fuente. Fotografía en vía pública (2008).

Figura 10. Imágenes para publicidad gráfica, campaña Much Music: "Del otro lado del mundo". Fuente. Genovese, A. (2007).

Figura 11. Fachada de comercio de indumentaria deportiva. Barrio de La Boca. Fuente. Fotografía en vía pública.

Figura 12. Afiches de campaña institucional Supermercados COTO: Fiesta Patrias. Fuente. Fotografía en vía pública (2008).

Figura 13. Carteles para vía pública, campaña publicitaria de cigarrillos Jockey Club. Fuente. Revista Infobrand (2009).

Figura 14. Gigantografía publicitaria, campaña de Rexona. Barrio de La Boca. Fuente. Fotografía en vía pública (2009).

Figura 15. Afiche publicitario, Campaña Guía del Mundial 2006 Diario deportivo OLE. Fuente. fotografía en vía pública.

Figura 16. Gigantografía publicitaria, campaña de Aiwa. Fuente. Genovese, A. (2007).

Summary: In the '50s, the "Fileteado" popular art breaks in Buenos Aires as a purely urban expression attached to automotive graphics decoration. This article reflects about the origin of this art expression, its life and style transformation in the scope of advertising communication in the 2000s. The article shows the different stages of the evolution of this artistic practice: it emerges as a decorative motif; then it is related to the first horse drawn vehicles; later, it gets solid as a sociocultural visual expression and discursive level; it get closer to other transportation such as trucks and buses; it is excluded by city urban regulations; and finally it gets new meanings in the passage to new media vehicles. The process finds a path from traditional media to advertising and mass media and to everyday individual objects (musical instruments, clothing, decorative items, etc.). Transposition, change of vehicle or language of a work or genre is recurrent and the "Fileteado" is supported in graphics, murals, decorative items and clothing. How yhis artistic expression is recovered by marketing communications? It is one of the questions that guide the exploration of its visual identity components.

Key words: advertising communication - Buenos Aires "Fileteado" - decorative motifs gender - popular art - semiotics - style. 
Resumo: Na década do '50, o fileteado aparece na arte popular de Buenos Aires como expressão urbana na decoração de carros. Desde uma mirada social e semiótica se reflete sobre seu nascimento, vida e transformação estilística sobre as margens da comunicação publicitária na década do 2000.

Esta prática atravessa diferentes etapas: surge como decoração, relaciona-se com os primeiros carros de tração a sangue, se instala como expressão sócio-cultural aos níveis visual e discursivo, se estreita com outros transportes como caminhões e ônibus, é excluído por uma proibição normativa e mais tarde se re-inventa na passagem a novas formas.

O processo descobre uma passagem aberta desde os veículos tradicionais até os meios massivos publicitários e até os objetos individuais cotidianos (instrumentos musicais, roupa, artigos de decoração, etc.). A transposição, a troca de suporte ou linguagem de uma obra ou gênero, se faz recorrente, e o fileteado suporta-se em meios gráficos, audiovisuais, murais, objetos de decoração e indumentária.

Como o que inicialmente manifesta-se com uma expressão artística é recuperado pela comunicação publicitária? É um dos questionamentos que guiam a exploração de seus componentes visuais de identidade.

Palavras chave: arte popular - comunicação publicitária - estilo - fileteado - gênero - motivos decorativos - sócio-semiótica - transposição. 